\title{
Comunicación

\section{Comunicación de riesgo y espirales del miedo ${ }^{1}$}

\author{
JORDI FARRÉ COMA ${ }^{2}$
}

La Comunicación de Riesgo es un campo emergente que surge de la necesidad de investigar qué tipo de información requiere la opinión pública en circunstancias de peligro, crisis o catástrofe. La formación de procesos de espirales del miedo constituye un frente inexplorado de lucha social por la emancipación tanto para las instituciones y organizaciones como para los públicos que conforman sus vidas cotidianas rodeados de riesgo percibido.

Palabras Clave: comunicación del riesgo, miedo, opinión pública, medios de comunicación, sociedad del riesgo.
Risk Communication is an emergent field which arises within the necessity of researching what kind of information requires public opinion in circumstances of danger, crises or catastrophe. The formation of spirals of fear constitutes an unexplored front of social struggle for emancipation for both institutions and organizations as well as for the publics that shape their everyday lives around perceived risk, potential danger, and emotional fears in a growing media-saturated environment.

KEY WORDS: risk communication, fear, public opinion, communication media, risk society.

\footnotetext{
${ }^{1}$ Este artículo fue elaborado en mi estancia de investigación en el DECS de la UdeG, en el verano del 2004. Aprovecho la ocasión para agradecer a los miembros del cuerpo académico su amabilidad y amistad infinita. Me hicieron sentir como en casa y sus ánimos son en buena parte la causa principal por la que escribí este artículo en un ambiente académico excepcional.

2 Profesor de Comunicación de la Universitat Rovira i Virgili (URV), Tarragona, Catalunya, España.

Correo electrónico: jordibernat@wanadoo.es.
} 


\section{LA MEDIATIZACIÓN DE LA CULTURA:}

\section{CULTURA DE RIESGO Y CULTURAS DEL MIEDO}

En el último tercio del siglo XX, la consolidación de los procesos de mediatización convierten nuestras culturas mediáticas en determinantes hasta el punto que las sociedades de la información y el fenómeno de la globalización de las redes estallan ante un mundo convulsionado por el desmoronamiento de la utopía comunista. La ficción de los bloques, sostenida en una especie de equilibrio frágil, se derrumba y parece conducirnos hacia la construcción de un nuevo orden internacional menos convulso. Nada de eso se cumplió. Más bien nos vimos abocados a un nuevo desorden internacional en el que, a los albores del siglo XXI, se confirman la imposición de la cultura de riesgo, la amenaza, la inseguridad y el miedo de una sociedad y un individuo en peligro. Como acertadamente señala Dominique Wolton:

La dificultad en el presente, tanto en lo referido a los países del Norte como del Sur, se debe a que es preciso reflexionar utilizando tres parámetros: identidad, cultura y comunicación. Esto altera no sólo las relaciones entre los diferentes niveles de cultura (de élite, de masas, media o popular), sino también la relación con los lazos sociales, la sociedad y la política. Sólo el surgimiento progresivo de una comunicación política contradictoria permitirá esclarecer un poco más esta cuestión de la identidad cultural colectiva que, en cierto modo, condensa todas las aspiraciones de nuestras sociedades: libertad e igualdad, individualismo y adhesión a una pertenencia colectiva, apertura y necesidad de raíces, modernidad y miedo a no formar parte de la tradición, mundialización y deseo de identidad nacional (Wolton, 2004:62).

Esta cultura del riesgo mediatizada desemboca en la formación de culturas del miedo que constituyen la culminación de una nueva realidad social que exige la profundización e interés en este campo emergente de investigación, tanto desde la configuración de las identidades colectivas como personales. La Comunicación de Riesgo como enfoque específico proyecta un reto enorme, como lugar de encuentro, para la teoría de la comunicación en diálogo con la teoría social. El desenmascaramiento de los nuevos instrumentos de disciplinamiento social que 
actores institucionales, grupos terroristas e intereses corporativos pueden manejar para el ejercicio del poder y el control, exigen el posicionamiento renovado de una teoría crítica capaz de dar respuesta a estas nuevas formas de dominación. Aunque, como señala Bauman, ahora es la esfera pública la que necesita ser defendida contra la invasión de lo privado y, paradójicamente, no para cercenar la libertad individual, sino para ampliarla. La misma transformación en la lucha por la emancipación urge en el campo de la comunicación de riesgo que se abre como nuevo campo de batalla, de gran calado, en defensa de la libertad, igualdad y fraternidad humana, que no puede cercenarse por la seguridad, la exclusión y el miedo a las culturas:

Como siempre, el trabajo del pensamiento crítico es sacar a la luz los muchos obstáculos que entorpecen el camino hacia la emancipación (Bauman, 2002:57).

Dejarse atrapar por las culturas del miedo supone la rendición individual y colectiva ante las crecientes incertidumbres generadas alrededor de la cultura del riesgo y de las contradicciones extremas de la globalización capitalista. Las consecuencias perversas del miedo afectan la confianza de la ciudadanía que se convierte en víctima, la credibilidad de las instituciones democráticas que ponen en cuestión su legitimidad y, en última instancia, al conjunto de los sistemas democráticos, incapaces de rearticularse atrapados en la jaula de hierro de la (in)seguridad. Un peligro potencial radica precisamente en que se generan nuevas modalidades de exclusión social en que las comunidades refugio se impongan como protectorado para promover las diferencias de los que están a salvo y los "otros":

La ausencia de un vínculo social con los miembros "legítimos" de la comunidad (o la prohibición de establecerlo) tiene una ventaja más: las víctimas "pueden ser expuestas a la violencia sin riesgo de venganza", es posible castigarlas impunemente - $\mathrm{o}$ al menos eso es lo que se espera mientras se declara exactamente lo contrario, pintando el carácter sanguinario y criminal de las víctimas con colores vívidos y enunciando recordatorios de que hay que cerrar filas y mantener en estado de alerta todo el vigor y la vigilancia de la comunidad-(Bauman, 2002:206). 
Quizás los debates en torno a la cultura y la comunicación mediada desde una visión europea y estadounidense deban ser revisitados a la luz opaca de estas nuevas versiones telúricas conformadas alrededor de la cultura del riesgo. Efectivamente, la cultura de masas, la industria de la cultura, la cultura popular y las culturas mediáticas se ven oscurecidas y atravesadas, hic et nunc, por la cultura de riesgo que, al desembocar hacia culturas del miedo, no implica más que el reflejo del miedo a las culturas. Paradójicamente, el tránsito hacia el siglo XXI, marcado por las innovaciones tecnológicas, los progresos científicos y la información funcional y eficiente, se debate ante una confusión de gran profundidad:

Dada esta peculiar interacción entre el riesgo real y el riesgo percibido, cuando éste crece por las revelaciones de los medios de comunicación -que aunque no sean alarmistas desde luego se están expandiendo, por lo que multiplican todos sus contenidos, incluidos los que siembran alarma social-, también puede crecer el latente riesgo real, si se suscitan expectativas capaces de favorecer la multiplicación de riesgos y de inhibir la capacidad colectiva de superarlos. Lo cual genera el efecto óptico de hacer pensar que si crece la percepción mediática del riesgo revelado es porque está creciendo la producción social -la construcción colectiva- del riesgo real. Así es como los medios se convierten sin quererlo en bomberos pirómanos, pues la publicidad del riesgo percibido contribuye a magnificarlo (Gil Calvo, 2003:39).

Esta reflexión simbólica desde un contexto de primer mundo contrasta con las realidades situadas en sociedades donde la violencia y los desastres tienen una presencia cotidiana con consecuencias trágicamente palpables. En latitudes como Latinoamérica existen contribuciones muy notables sobre desastres naturales como erupciones volcánicas y terremotos que tratan de riesgos bien reales. Otras, muchas también muy reales, intentan comprender las raíces de la violencia en forma de delincuencia y asesinatos sistemáticos en muchas de las grandes ciudades de esta región. En este sentido, la investigación de Reguillo (1999) sobre la construcción simbólica de la ciudad es ejemplar respecto a cómo la ciudadanía de Guadalajara incorporó la cultura del riesgo a partir del desastre de las explosiones de gas sufridas en la ciudad el 22 de abril de 1992. 
En otro sentido diferente, la cuestión del riesgo percibido y la cultura del miedo entre la población regalada de bienestar de las sociedades avanzadas apunta hacia debates más profundos y conflictivos en torno al proyecto mismo de modernidad, tal y como señala Reguillo al inscribir su investigación:

La racionalidad moderna, fundada en la premisa del progreso científico y técnico, en el triunfo de la razón como revelación de la verdad objetiva, en una concepción lineal de etapas o fases para acceder a la modernidad, se enfrenta en este tiempo a la crisis de su paradigma que se manifiesta en el estallamiento creciente de conflictos sociopolíticos derivados de la desigualdad, en el regreso de cierto tipo de fundamentalismos que la razón moderna creía erradicados, en el desdibujamiento del sueño iluminista que creía que el progreso era la llave para conquistar un desarrollo equitativo, armónico y ascendente (Reguillo, 1999:27).

\section{TEORÍA SOCIAL Y TEORÍA DE}

\section{LA COMUNICACIÓN DE RIESGO}

La Sociedad de riesgo que Ulrick Beck analizaba en su libro de 1986, edición original en alemán Risikogesellschaft: auf dem Weg in eine andere Moderne, ${ }^{3}$ coincidió en el tiempo con la catástrofe nuclear de Chernobyl y de hecho se correspondía con sus escritos sobre la irresponsabilidad organizada de una etapa del capitalismo donde la producción y centrifugación de los peligros se constituía como su principal dinámica de funcionamiento. Ya en la década de los noventa, la teoría social de Beck entró en diálogo con otras aportaciones de Habermas, Giddens, Wallerstein, entre otros, para tratar de integrar las consecuencias de la caída del Muro de Berlín y la desintegración del socialismo real. En esta segunda coyuntura destacan las tesis sobre la modernización reflexiva y la globalización, con el estudio de lo que el sociólogo de la Universidad de Munich bautizó como "Segunda Modernidad". El tercer periodo de las obras de Beck podemos situarlo a partir de los atentados del 11 de septiembre de 2001 en Estados Unidos y el ciclo bélico con el que se relaciona contra el terrorismo difu-

3 Edición en español Beck, 1998. 
so. Nos referimos a obras como Sobre el terrorismo y la guerra (2002) y Poder y contrapoder en la época global (2002).

Desde una reflexión abstracta de teoría social, los teóricos del riesgo, con Beck como observador privilegiado, nos dibujan una época global donde el Estado ya no define y transforma la acción colectiva. La política cambia de ubicación desfronterizada y abierta a nuevos actores, papeles, recursos, reglas desconocidas, nuevas contradicciones y conflictos. Los nuevos actores globales, entre ellos los grupos terroristas, las multinacionales, las estructuras supranacionales, las normativas internacionales, las Organizaciones No Gubernamentales (Al Qaeda, la ONU, la Unión Europea, el MERCOSUR, International Standard Organization, ISO, el Tratado de Libre Comercio de América del Norte, Greenpeace, Amnistía Internacional, etcétera) abren nuevos retos para el posicionamiento de la Teoría Crítica. De hecho, la desubicación de la Teoría Crítica exige nuevos frentes de lucha por la emancipación humana. Las aportaciones de Zygmunt Bauman y Ulrich Beck en este sentido resultan paradigmáticas.

En el caso de Bauman, la cuestión clave reside en la recuperación del espacio público que se está vaciando debido a la deserción de los "ciudadanos interesados" y a la huida del poder real hacia un "espacio exterior":

Y por lo tanto, en el espacio público hay cada vez menos temas públicos. Fracasa a la hora de cumplir su pasado rol de lugar de encuentro y diálogo entre problemas privados y asuntos públicos. Víctimas de las presiones individualizadoras, los individuos están siendo progresiva pero sistemáticamente despojados de la armadura protectora de su ciudadanía y expropiados de su habilidad e interés de ciudadanos. En estas circunstancias, las perspectivas de que el individuo de jure se transforme en un ciudadano de facto (o sea, aquél que controla los recursos indispensables de una genuina autodeterminación) son cada vez más remotas.

El individuo de jure no puede convertirse en un individuo de facto $\sin$ primero convertirse en ciudadano. No hay individuos autónomos sin una sociedad autónoma, y la autonomía de la sociedad exige una autoconstitución deliberada y reflexiva, algo que sólo puede ser alcanzado por el conjunto de sus miembros (Bauman, 2002:46). 
Complementariamente con Beck, el riesgo global hace presente la epifanía de la barbarie. La Segunda Modernidad se nutre del riesgo como una manera sistemática de negociar el azar y las inseguridades introducidas por la propia modernización. El mito del progreso se derrumba y nos acercamos a la inseguridad social y al riesgo de la ignorancia en las sociedades de la información. El proceso de individualización nos lleva al desconcierto, la anomia y la ansiedad individual y colectiva. El liberalismo esquizofrénico retratado por Beck nos sumerge en grandes paradojas como las de unas fronteras inexistentes para el capital, pero cerradas para la fuerza de trabajo o la apertura radical hacia un mercado mundial con una política proteccionista hacia el interior.

En La sociedad del riesgo global (2002), Beck sostiene que, en la actualidad, nuestras sociedades se definen por una "irresponsabilidad organizada" que ampara a los productores del riesgo a costa de sus víctimas y hace que los riesgos reales resultantes acaben siendo invisibles. Urge la expansión de una ciudadanía cosmopolita (a no confundir con la gestación de una clase emergente de gestores globales), capaz de abordar la dialéctica de las cuestiones globales y locales. De ahí la propuesta ambiciosa de Beck del Manifiesto Cosmopolita como nueva alternativa para la Teoría Crítica. En cierto sentido, se trata de la recuperación del grito liberador de la Ilustración, ;Sapere Aude! (¡Atrévete a pensar!), en la estela que dejó el filósofo alemán Kant en su obra Idea de una historia universal en sentido cosmopolita (1784). ${ }^{4}$

Ni más ni menos, el legado de la razón y de las luces es puesto en cuestionamiento por una sociedad del riesgo donde los ciudadanos atemorizados dejan de serlo para convertirse en víctimas de lo telúrico. Efectivamente, las amenazas y las incertidumbres en un entorno de percepción de riesgo se ciernen sobre nuestras sociedades de individuos y nuestras democracias. Bauman, citando a Beck, reflexiona sobre la necesidad de actuar en un tema tan espinoso y complejo:

Beck escribe: "Eliminar riesgos, o interpretarlos para hacerlos desaparecer, es para la conciencia del peligro lo mismo que el alimento para el

$\overline{4}$ En la recuperación de este precedente ilustre como posible solución a los problemas de la globalización, coinciden tanto Bauman como Beck. 
hambre". En una sociedad acosada fundamentalmente por la carencia material, la opción entre "eliminar la miseria" o "interpretarla para hacerla desaparecer" no existe. En nuestra sociedad, más acosada por el riesgo que por la miseria, sí existe y se opta a diario. El hambre no puede apaciguarse con el rechazo: en el hambre, el sufrimiento subjetivo y su causa objetiva están indisolublemente unidos, y el vínculo es evidente y no puede negarse. Pero los riesgos, a diferencia de la carencia material, no se experimentan subjetivamente; al menos, no es posible "vivirlos" directamente, sin la mediación del conocimiento. Pueden no llegar jamás al campo de la experiencia subjetiva, pero ser trivializados o negados antes de llegar allí, y la posibilidad de que se les impida llegar a ese campo crece a medida que el grado de riesgo aumenta (Bauman, 2002:221).

Cabe señalar que este tipo de patologías sociales del riesgo percibido encajan con las dinámicas del primer mundo y, por tanto, en tal contexto es donde debe enmarcarse esta construcción social y cultural del riesgo. No obstante, el uso del miedo como estrategia de disciplinamiento social es un recurso muy utilizado por los gobernantes en los países sin una democracia estable y con una cultura cívica poco consolidada. La desigualdad ante esta cuestión entre unas partes y otras del planeta es evidente y merecería un estudio intercultural detallado y en profundidad.

\section{ACERCAMIENTO DISCIPLINAR}

\section{A LA COMUNICACIÓN DE RIESGO 5}

Existen desacuerdos substanciales para llegar a un significado compartido sobre lo que es el riesgo. Aun así pueden identificarse propuestas generales bien delimitadas que explican el enfoque inicial del campo de

5 En el ámbito de la Unidad Predepartamental de Comunicación de la Universidad Rovira i Virgili (URV) de Tarragona, hemos impulsado una serie de iniciativas que sitúan esta línea de investigación como prioritaria para nuestro territorio y como punto de referencia para nuestras propuestas académicas y de reflexión teórica y empírica: en primer lugar, impartimos en nuestro plan de estudios una asignatura de Comunicación de Riesgo y de Crisis, así como realizamos un curso de verano en este ámbito; en segundo lugar, vamos a programar una maestría de Especialista Universitario en esta temática a desarrollar a lo largo del año académico 2005-2006 (240 horas) y, en último lugar, the last but not least, 
la comunicación de riesgo. En un extremo, la perspectiva de aquéllos que pretenden encontrar una definición del riesgo como propiedad objetiva de un acontecimiento o actividad y cómo se hace posible su medida o cálculo, la probabilidad de ocurrencia. En esta forma, el riesgo se presenta como claramente definible: el riesgo es la probabilidad cuantificable de que se produzca un acontecimiento adverso con consecuencias trágicas o negativas para el ser humano. En el otro extremo, la perspectiva constructivista que entiende el riesgo como las percepciones subjetivas del riesgo filtradas por la cultura y por la estructura social. La versión más dura de esta versión desemboca en una especie de relativismo que prácticamente hace desaparecer el riesgo que solamente se manifiesta a través de sus percepciones.

En cierto sentido, tanto la perspectiva objetiva como subjetiva del riesgo, entendidas aisladamente, acaban conformando distinciones empobrecedoras de la realidad. Debemos asumir que ciertos estadios de la existencia que son posibles pero no predeterminados pueden, objetivamente, ser definidos como riesgo. En consecuencia, estos estadios se mueven en el terreno de las probabilidades e implican un cierto grado de incertidumbre. Pero también aquello que los individuos o las sociedades perciben como riesgo, y deciden asumirlo de esa manera, no puede ser reducido a criterios objetivos, sino que debe tomar en cuenta factores sociales, culturales, políticos y económicos. A la idea de posibilidad e incertidumbre cabe añadir que el riesgo existe solamente cuando implica una característica sobre el mundo, ya sea en sucesos naturales o en actividades antropomórficas, que tiene una influencia negativa e imprevisible sobre la realidad humana. El cálculo de probabilidades no puede asegurar de ninguna manera el riesgo cero. El impacto sobre el medio ambiente de cualquier desastre, la aparición inesperada de una enfermedad o, en último término la muerte, ponen en juego los valores más

hemos presentado un proyecto de investigación a las convocatorias competitivas del Ministerio de Ciencia y Tecnología de España para llevar a cabo el proyecto de investigación: "El proceso de comunicación de riesgo en Tarragona: Análisis de la percepción y la recepción social del riesgo petroquímico. Participación pública, comunidad local y comunicación de proximidad". Este proyecto ha sido evaluado favorablemente y tendrá una duración de tres años (2005-2007). 
preciados para los humanos y siempre estarán sometidos a una dosis relevante de incertidumbre.

Sin embargo, si defendemos que el riesgo no existe como una realidad ontológica, sino que es más bien una realidad epistemológica, esto implica que el riesgo existe sólo cuando lo reconocemos como tal. Es decir, el riesgo no puede distinguirse de la percepción del riesgo porque es imposible diferenciar riesgo real de riesgo percibido. Los que no percibimos no existen porque los desconocemos. A la luz de este argumento, existe el peligro de cargar las tintas sobre el concepto de percepción en una especie de reducción psicologista, olvidando que la definición del riesgo tiene lugar en el contexto social donde se acuerdan las bases para su domesticación.

La consolidación de la comunicación de riesgo como una disciplina de interés estratégico para la teoría de la comunicación obedece a la centralidad y transversalidad característica de sus procesos holísticos de mediación. Aun así, como objeto y sujeto de estudio se encuentra en sus fases iniciales de formación, tal y como sucede con la comunicación política:

"Abordar la comunicación política como un tema de estudio es algo nuevo y por tanto no existen conceptos claros; entenderla como un espacio, una disciplina, o un recurso plantea ambigüedades que no son sencillas de resolver (Razgado, 2002:109).

De hecho, la Comunicación de Riesgo debe ser diferenciada de otras líneas sectoriales que se interesan por identificar conflictos parciales. Así por ejemplo, la información de crisis se ocuparía básicamente de los protocolos de actuación que se deben seguir en situaciones planificadas y predefinidas o la comunicación de crisis se encargaría de las relaciones entre la comunicación empresarial y los medios de comunicación social fundamentalmente. En el primer caso, la cuestión revierte en las organizaciones comunicativas y atañen a la especialización periodística hasta el punto de llegarse a plantear la necesidad responsable de conformar un periodismo de crisis capaz de reaccionar equilibradamente ante situaciones de crisis a través de la información, de las rutinas de producción y de las prácticas profesionales. En el segundo caso, la comunicación de crisis 
es una de las áreas de la comunicación institucional y organizacional que actúa como herramienta para la defensa de la identidad institucional ante los procesos de ofertas y demandas informativas:

A pesar del papel clave que las relaciones públicas desempeñan en la gestión de las crisis, potenciales o reales, no se ha hecho gran esfuerzo para tratar con situaciones críticas de un modo sistemático y previsor. Sólo compañías que tienen una clara vulnerabilidad para la crisis parecen estar preparadas para afrontarlas, mientras las demás adoptan una postura reactiva. Sin embargo, las crisis son un fenómeno que las organizaciones pueden prever y al que se le pueden reducir sus efectos negativos (Burnett, 1998:487).

Por su parte, el cálculo objetivo del riesgo preocuparía principalmente a los expertos o científicos a partir de una racionalidad científico-técnica y a los gestores políticos tratando de domesticarlo desde una racionalidad burocrático-gestora, entendiéndola como un recurso. A pesar de la validez y utilidad de estos acercamientos parciales, existe una problemática más relevante aún y que tiene que ver con otras dos racionalidades básicas: por un lado, la racionalidad subjetiva-social que presenta como marcos referenciales los valores éticos y morales, ideológicos, políticos y que, en última instancia, reflejan un problema central de teoría social, la imbricación de los modelos de persona y de sociedad; por otro lado, la cuestión del rol de los medios de comunicación como amplificadores sociales del riesgo que afecta, en términos de magnificación o atenuación, la percepción social del riesgo que puede tener la población, la opinión pública, la audiencia, los ámbitos de la recepción.

En los procesos de comunicación de riesgo como campo emergente confluyen los grandes dilemas que la teoría de la comunicación crítica debe de afrontar en nuestros tiempos: la dialéctica local-global, las aproximaciones macro-micro, los planteamientos objetivos y subjetivos, etcétera. En definitiva, la lógica de la estructuración de un campo académico emergente apoyado en la teoría de los campos y la hermenéutica profunda. En otras palabras, en diálogo permanente con las discusiones básicas de teoría social, muy en consonancia con lo que Raúl Fuentes plantea refiriéndose a la teoría de la comunicación, la Comunicación de Riesgo debe de afrontar los mismos retos y dilemas: 
De esta manera, una adaptación del "marco metodológico de la hermenéutica profunda" (con que Thompson analiza la comunicación de masas y la ideología) permite articular los propósitos generales (praxeológicos, autorreflexivos) con los objetivos científicos de este proyecto; los postulados teórico-metodológicos adoptados de las teorías de la estructuración y de los campos con los diversos métodos (cuantitativos y cualitativos) de análisis empleados, y el sentido subjetivo del trabajo con el principio de la “objetivación participante (Fuentes, 1998:66-7).

Siguiendo los enfoques de la comunicación política que Razgado (2002) identifica, la Comunicación de Riesgo puede entenderse desde cuatro enfoques: el de la influencia (análisis de los efectos), el del contenido, el de la persuasión y el de los actores. Pondremos atención en el primero y el último que se presentan como los más relevantes para el campo.

Por un lado, desde la investigación de los efectos cognoscitivos, cabe mencionar las contribuciones empíricas de la Hipótesis de las brechas del conocimiento (The Knowledge Gap Hypothesis) y el Análisis del cultivo (The Cultivation Analysis).

La primera evidencia cómo, para conocer la efectividad de una campaña informativa, es indispensable controlar factores y situaciones específicas como el grado de conflicto sobre el tema o los rasgos específicos de la comunidad. En cualquier forma, ocurre que estas campañas pueden provocar el efecto contrario a lo previsto, es decir, aumentar las brechas entre los pocos que conocen el mensaje y la gran mayoría que no accede al conocimiento del mismo. En consecuencia, muchas de las lógicas institucionales no toman en cuenta que no es suficiente con el diseño de una buena campaña informativa para lograr los objetivos, sino, antes al contrario, se pueden provocar los efectos opuestos a los pretendidos, alejando del conocimiento y del interés a aquéllos que no se sienten afectados.

En el segundo caso, Gerbner y sus colaboradores en la Universidad de Pennsylvania demostraron empíricamente que la relación causal entre violencia y televisión no era posible, ni tan solamente, de conjeturar porque existían otros muchos factores como el contexto social y cultural. No obstante, se dieron cuenta que se producía, en casos concretos, una evidente distorsión de la realidad mediática (en televisión aparecen muchos más delitos sexuales cuando en la realidad los más 
numerosos son los delitos contra la propiedad) y una cierta interiorización, por parte de los espectadores, del miedo, asociándose a un mayor grado de inseguridad individual, dadas unas condiciones determinadas, de exposición a la televisión.

En este marco es interesante la propuesta ordenadora que nos presenta Patrick Charaudeau (2003) sobre el discurso de la información. El lingüista del discurso francés identifica tres lugares de pertinencia de la máquina mediática, inscritos en una problemática de la influencia donde intencionalidad y construcción del sentido participan en la estructuración del espacio público: lugar de las condiciones de producción, lugar de construcción del discurso, lugar de interpretación. Así pues, la investigación de los efectos de los medios debe considerar la complejidad en la relación entre los "efectos propuestos", los "efectos posibles", los "efectos supuestos" y los "efectos producidos":

Por lo tanto, éstos no representan únicamente la intención del productor de la información, ni tampoco la del receptor. Tal situación no impide que estos tres lugares se definan unos en relación con los otros, y que si los efectos propuestos, los posibles y los supuestos son estrictamente solidarios, los efectos producidos por "retorno de imágenes" tengan alguna incidencia sobre el acto de producción con la condición, sin embargo, de que esta instancia tenga conocimiento de ello (Charaudeau, 2003:29).

Por otra parte, desde el enfoque de los actores, la Comunicación de Riesgo como proceso incluye: el público en general, las comunidades locales afectadas, las autoridades públicas, los profesionales de la industria, los expertos científicos y técnicos, las organizaciones civiles o medioambientales y los medios de comunicación. Todos ellos se aproximan a las potencialidades asociadas con las situaciones de riesgo a partir de una progresiva hibridación de los niveles de comunicación. El nivel micro, intrapersonal o interpersonal se fusiona con los estadios intermedios, nivel intra e intergrupal o nivel de las organizaciones, para imbricarse finalmente con los niveles macrosociales, nivel de la comunicación mediada y de la opinión pública. Asimismo es interesante reseñar la confusión en los ámbitos de actuación, competencia, responsabilidad e influencia: ámbito local, rural, urbano, regional, estatal, supraestatal, global, mundial, planetario. 
Todo este conjunto de factores son determinantes para reivindicar y concebir una aproximación holística a la complejidad de las percepciones de riesgo en nuestras sociedades mediáticas. Nos encontramos en la etapa de la posdisciplinaridad como Fuentes (2002) apunta para la concepción crítica del campo de la comunicación, o bien como Reguillo (2002) desenmascara al señalar las relaciones entre las políticas de representación y las configuraciones del poder que deben de afrontarse desde la antropología de la comunicación. ${ }^{6}$

\section{MIEDOS Y MEDIOS}

Nuestras vidas cotidianas se encuentran rodeadas por riesgos potenciales con los que convivimos voluntariamente. Fumar produce importantes riesgos para nuestra salud, circular por carretera presenta una alta probabilidad de accidentes e incluso de muerte. Este tipo de riesgo es voluntario y se encuentra integrado en nuestras decisiones del día a día de tal manera que, de tan visibles, se convierten en invisibles. Por el contrario, la cuestión se torna distinta respecto a cómo percibimos nuestro entorno a partir de los procesos de mediación estructural a los que nos someten los medios de comunicación. Muchos de estos riesgos mediatizados se nos presentan como invisibles, difusos, que pueden ser muy visibles en sus consecuencias en la toma de decisiones cotidianas. Paradójicamente, si como audiencias conocemos que los pollos asiáti-

6 A partir de una investigación comparativa en distintas ciudades de Latinoamérica, Rossana Reguillo aborda el poder reconfigurador de los miedos en las ciudades contemporáneas. Reguillo nos previene, en sus palabras textuales, que existen dos consignas que operan como claves expandidas de intelección del mundo y que no sólo contribuyen a la erosión del tejido social, sino que además funcionan como "coartadas" en dos direcciones: "Desde arriba" justifican y celebran el autoritarismo, los discursos y las prácticas de vigilancia y control, hoy globalizadas, que han encontrado en el desencanto, en la vulnerabilidad y en el temor hacia el futuro, un filón para imponer un modelo que no acepta contestación alguna; "desde abajo”, operan como ratificación de lo que los teóricos de la modernidad tardía denominan "inadecuación biográfica del yo", cuya traducción es a la vez compleja y muy elemental: todos estamos mal y no hay espacios de escapatoria, ni prácticas a prueba de la asunción de estas "verdades". 
cos han enfermado con fiebres altas, los mercados mayoristas de venta de alimentos en Barcelona se resienten en el descenso de las compras de esta ave de corral. Este proceso indica cómo pasan de ser riesgos percibidos a tener consecuencias en términos de inseguridad, incertidumbre, miedo. Precisamente, este tránsito es el que nos va a ocupar: los riesgos serán reales si se definen como tales, pero también aun siendo virtuales sus consecuencias pueden bien ser muy reales. Las implicaciones políticas en esta cuestión son enormes.

En todo este juego de formación de espirales del miedo, podemos alinear dos posturas contrapuestas respecto al rol que desempeñan los medios, actores centrales en la configuración del espacio público. A partir de 1970, los estudios del comunicador empiezan a escudriñar el quehacer cotidiano de este oficio en sus operaciones de selección, jerarquización y evaluación de los discursos de la información. En particular, se incide sobre las prácticas rutinarias de producción y los valores profesionales noticiosos. Incluso se llega a diagnosticar que los periodistas se han convertido en especialistas en la rutinización de la imprevisibilidad. Estas investigaciones resultan muy pertinentes para comprender qué papel adoptan los profesionales en la configuración de los procesos de comunicación de riesgo. En forma sintética podemos identificar los siguientes criterios en la selección y tratamiento de las noticias, incluidas las referidas a temáticas de riesgo:

1. Una clara orientación hacia los acontecimientos novedosos, con consecuencias rupturistas y a gran escala.

2. Que reflejan situaciones dramáticas y conflictivas o que pueden ser traducidas a marcos y escenarios familiares para la audiencia.

3. Con un alto grado de personalización, de domesticación para ser encajados en los marcos interpretativos de la vida cotidiana y de visualización, con imágenes que permitan la cristalización temática del acontecimiento.

En este contexto parecería obvio que los medios de comunicación son fuentes importantes en la amplificación social de las percepciones de riesgo: ya sea por su negatividad, distorsión, sensacionalismo, dramatización o exageración de las temáticas que, en un primer momento, 
descontextualizan para, en un segundo momento, recontextualizar en sus formas informativas. En particular, esta presunción es asumida de forma impresionista por todos aquellos actores (expertos, políticos, ciudadanos) que desconocen la complejidad de los procesos de comunicación mediada y las operaciones instrumentales de los medios.

La cuestión como vamos a tratar de desentrañar no es tan simple. Las evidencias empíricas obtenidas por Graham Murdock et al. (2001) en Inglaterra y David Altheide (2002) en Estados Unidos nos servirán de atalaya privilegiada para la fundamentación de la discusión. En primer lugar, en la investigación de Murdock et al. (2001) se sostiene que el campo de la comunicación de riesgo está transformándose radicalmente por tres razones:

a) El incremento sustancial de las Organizaciones No Gubernamentales (ONGs), tanto en el ámbito de los grupos ecologistas como en el sector de los consumidores. Su papel es crecientemente activo e invierten estratégicamente para acceder a las agendas públicas de los medios, en lucha por la visibilidad y legitimidad.

b) En los últimos tiempos hemos asistido a un crecimiento muy notable en la escala de las actividades de las relaciones públicas, tanto en los sectores gubernamentales como corporativos. Este deslizamiento en los oficios de la comunicación ha conllevado en paralelo el distanciamiento mayor por parte del público que responde con desconfianza y con una actitud de sospecha frente a las prácticas de mercadotecnia y asesoría corporativa.

c) La irrupción de Internet ha proporcionado nuevas fórmulas de acceso directo al público sin la mediación de las organizaciones mediáticas convencionales. El panorama de los medios apunta a grandes mutaciones donde las computadoras, la televisión digital o los celulares pueden contribuir como nuevos medios para el acceso personalizado a la información.

A pesar del conjunto de estas transformaciones que ofrecen nuevas oportunidades y retos para la comunicación de riesgo, la opinión pública continúa accediendo mayoritariamente al espacio público a través de la prensa, la radio y la televisión. Aun así, el reconocimiento de la nece- 
sidad de configuración de la esencia del contenido de la información en términos de aquello demandado por el conocimiento y las preferencias de los públicos, activos en su interpretación, se refrenda además con la complejidad y diversidad de los propios medios:

En general, nuestra evidencia nos lleva a refutar cualquier sugerencia sobre que los públicos legos son receptores pasivos del conocimiento experto del riesgo. La gente quiere sentir que los riesgos que son significativos para ellos están siendo atendidos y esto significa tomar control personal donde el control facilita la toma de decisiones sobre si comprar cierta comida o no, o usar ciertos medios de transporte o no-. Se demanda que ellos racionalicen la información en una forma significativa para facilitar sus mecanismos de asunción. Inevitablemente, este proceso de racionalización les obliga a extraer interpretaciones y fuentes múltiples de información (Murdock et al., 2001:91).

En cierto modo, en esta investigación británica, los medios aparecen como marcos de interpretación sofisticados con estrategias plurales en la cobertura de los temas de riesgo. Se sugiere que los medios no son el problema, sino más bien la oportunidad para acercarse a una audiencia selectiva alimentada por sus propios contextos socioculturales. Por lo tanto, los medios son un recurso para los comunicadores de riesgo que pueden sacar provecho de las narrativas, las imágenes, la domesticación y la personalización de las consecuencias del riesgo percibido para ahuyentar la formación de las espirales del miedo:

Los medios no son transmisores de la información oficial de riesgo, sino intérpretes y mediadores activos, intermediarios en el campo de juego, los cuales buscan conectar con las preferencias e intereses sociales y al hacerlo ponen en juego y mantienen su posición. Son gestores activos del significado convirtiendo el material en bruto de la información oficial y los acontecimientos en productos que comportan sus particulares 'cuotas' de mercado y estilos de presentación (Murdock et al., 2001:94).

En síntesis, este estudio británico desde una aproximación cualitativa, basada en la aplicación de técnicas como entrevistas en profundidad y grupos de discusión, presenta tanto a las audiencias como a los 
medios de una forma activa en un proceso simbólico dinámico, sofisticado y lleno de matices. Ambos son creativos y, en ningún caso, debe simplificarse la comprensión del rol y la influencia de los medios en la amplificación social de la percepción de riesgo. En todo caso y muy a menudo, la acusación contra los medios es más bien una válvula de escape en el agravamiento real de las tensiones entre los expertos, los gestores del riesgo y los públicos legos. Y, en buena parte, este falso debate suele obedecer al fracaso en la comprensión coherente y plena del impacto y procedimiento del sistema de información, complejo y plural en sus relaciones con las audiencias.

En otro planteamiento, David Altheide presenta una investigación para contextualizar la naturaleza y el uso de la palabra "miedo" en los medios de comunicación de Estados Unidos. En Creating Fear. News and the Construction of Crisis, este sociólogo de la Universidad de Arizona defiende, desde una aproximación interpretativa, que la lógica mediática a través de sus formatos contribuye significativamente a la construcción del miedo en el contexto de comunidades mediadas en su identidad y definición de situación:

"El miedo juega una parte esencial en el control social. Existen diversas razones para ello. Primero, examinamos el proceso que hace funcionar el control social. Las cosas que tememos guardan relación con cómo nos comunicamos y aprendemos en la vida cotidiana (...) La vida social en los Estados Unidos y la mayoría de las sociedades industrializadas han derivado hacia una "sociedad del riesgo", organizada alrededor de una comunicación orientada a la vigilancia policial, el control y la prevención de riesgos (Altheide, 2002:14).

A pesar que la conexión causal de los medios y las percepciones públicas del miedo es difícil de establecer aisladamente, con toda probabilidad asistimos a una relación circular en la que, cuanto mayor miedo de peligro potencial se experimenta en el ambiente social, las personas deciden permanecer más tiempo en sus casas donde, a su vez, se exponen con mayor asiduidad a los medios que les cuentan historias que refuerzan sus ansiedades. Sin embargo, lejos de una acusación desmesurada contra los medios, Altheide apunta que podemos dudar que los medios desempeñen un rol central en los miedos y las percepciones del riesgo porque de 
hecho, es importante recordar que los medios amplifican o atenúan, pero no causan el sentido del riesgo en la sociedad. A pesar de lo cual existe una disposición hacia la expectativa de consecuencias adversas que los medios integran en sus formatos. El resultado es que los medios siempre están a punto para alertarnos de algún tipo de peligro, aunque esta preocupación mediática de alerta de riesgos sea el síntoma del problema y no su causa. Sería del todo improbable que un público relajado y plácido, con altas dosis de sentido común, fuera influido hacia un estado permanente de pánico a través de la manipulación de los medios.

El problema reside en cómo las audiencias han integrado el miedo a sus vidas cotidianas y participan de una cultura popular e informativa donde el miedo se convierte en parte del lenguaje, dado por supuesto. Metodológicamente, Altheide rastrea el discurso del miedo a través de los medios aplicando una técnica cualitativa e interpretativa de análisis de contenido:

Tracking discourse es una aproximación para investigar la organización, estructura, denotaciones y connotaciones de las coberturas de los medios a lo largo del tiempo. Se trata de un instrumento útil para comprender cómo los significados culturales han cambiado en relación al miedo y, más importante, cómo el miedo se convierte en una perspectiva general en la discusión pública y en las visiones de la vida social. Tracking discourse es una perspectiva como muchos de los métodos que han sido inspirados por cuestiones planteadas por sociólogos de la cultura sobre las definiciones sociales en transformación. Como tal, puede ser útil en la observación sistemática de cambios en el lenguaje público y en la supervisión de cómo la terminología del control social y las perspectivas (por ejemplo, el miedo) son ordenadas e integradas a través de los diversos temas públicos (Altheide, 2002:39-40).

Aunque los miedos han convivido siempre con nosotros, su magnitud y naturaleza es hoy distinta. El círculo del miedo, gracias al trabajo de los medios y la cultura popular, se ha convertido en el encuadre desde el cual evocamos los procesos de victimación de los otros en unas sociedades secularizadas donde el miedo a Dios ya no nos lleva a la salvación. Como conclusión cabe diferenciar la percepción del riesgo del concepto de miedo. El miedo es una emoción, una orientación general 
donde el peligro es inminente y la respuesta única consiste en evitar la fuente del miedo o atacar el objeto que lo provoca:

El miedo es fundamentalmente una experiencia psicológicamente diferente del riesgo percibido. Mientras que el riesgo implica un juicio cognoscitivo, el miedo es mucho más emotivo en carácter. El miedo activa una serie de transformaciones corporales complejas que alertan al actor de la posibilidad de peligro (Ferraro, citado en Altheide, 2002:188).

En el campo de la cultura de masas es muy ilustrativo el trabajo documental de Michael Moore, Bowling for Columbine (2002). El realizador plasma ácida y brillantemente la creciente paranoia de la sociedad de Estados Unidos ante una inseguridad ontológica galopante muy vinculada con los miedos y los medios.

\section{LA PERCEPCIÓN Y RECEPCIÓN SOCIOCULTURAL DEL RIESGO}

La complejidad, pues, de la Comunicación de Riesgo no puede soslayar el estudio de la percepción y la recepción sociocultural del riesgo. En las primeras formulaciones de este campo de investigación, la principal interrogante consistía en ver de qué forma podían acercarse las visiones contrapuestas respecto a la percepción desigual del riesgo por parte de los expertos y científicos en comparación con la ciudadanía y las comunidades afectadas que interpretaban el riesgo según sus contextos sociales y culturales específicos. Existía un divorcio epistemológico entre el cálculo objetivo y la gestión efectiva en relación con la visión subjetiva, cotidiana y de sentido común. ¿Pero qué ocurre en nuestros tiempos?:

Éste es el punto de partida del siglo XXI: la ruptura entre información y comunicación, la dificultad para pasar de la una a la otra. Sabíamos que las culturas eran diferentes, pero pensábamos que la misma información podía ser más o menos aceptada por todos. Advertimos lo opuesto: entre información y comunicación se abre un abismo. Esta verdad empírica había sido descubierta, muchas veces con dolor, a escala de los Estados nacionales; se le encuentra más claramente a escala del mundo. Lo que se desmorona es un determinado modelo universalista -en realidad, occidental- de la información y el vínculo entre información y comunicación. 
Porque ese vínculo ya no responde a la misma necesidad: desde la caída del comunismo, que estimuló cierta libertad de prensa en todo el orbe, y desde que se ingresó en una era donde la abundancia de la información está económicamente justificada, el lazo directo entre la información y su aceptación por los destinatarios se ha debilitado. La información está ligada al mensaje y presupone su aceptación. La comunicación, en cambio, pone el énfasis en la relación y cuestiona, por tanto, las condiciones de la recepción (...) (Wolton, 2004:23).

En suma, el campo de la comunicación de riesgo presenta importantes conexiones con el estudio de los medios y con el procesamiento de la información organizacional. La relevancia teórica y práctica de la investigación de la comunicación de riesgo se encuadra en la creciente diversidad de estrategias de información. En la sociedad del riesgo se han multiplicado las posibilidades mediáticas hasta el punto que la disponibilidad de nuevas tecnologías para el uso privado, como los teléfonos celulares o el intercambio de información a través de internet o de otros dispositivos comunicativos, constituyen elementos fundamentales para el campo de la Comunicación de Riesgo. De hecho, Wolton apunta que estos nuevos dispositivos simbolizan la paradoja de que cuanto más necesidad de navegación en las redes experimenta la humanidad, más necesita hablarse:

En realidad, la aparición de la convivencia cultural como apuesta política de la tercera mundialización ilustra las dos filosofías de la comunicación, técnica y política, que se oponen desde hace mucho tiempo. La primera cree que, fundada en las técnicas y en las promesas de los mercados, podrá generar una sociedad de la información donde individuos y colectividades, formando una vasta comunidad, circularán libremente por las redes. La segunda busca más bien, partiendo de una definición humanista y política de la comunicación, sentar las bases de la intercomprensión organizando una convivencia entre culturas.

Las dos últimas décadas del siglo XX estuvieron dominadas por la visión técnica y económica de la comunicación. El comienzo del siglo XXI, con los conflictos y el terrorismo, recupera la importancia de una definición humanista y política a su respecto (Wolton, 2004:191).

En términos sociales, el clima comunicativo debe promover confianza y credibilidad en la información requerida que, en cualquier cir- 
cunstancia, debe emerger del problema del proceso de recepción en particular y de la percepción del riesgo en general. Por lo que la disponibilidad de la información debe ser el resultado de un proceso de comunicación en doble dirección, donde la participación pública sea el factor esencial gracias al cual los responsables institucionales puedan actuar con mayor eficacia. La ecuación clave para una evaluación pertinente se sustenta en la percepción y la recepción social del riesgo derivada del derecho de la ciudadanía a recibir, buscar y encontrar la información por sí misma, así como en el derecho de participar en el proceso de toma de decisiones.

De forma distintiva, la Comunicación de Riesgo se plantea como un proceso en su totalidad con una lógica que debe promover el diálogo y que, en ningún caso, debe ser absorbida por el control de intereses particulares. Su conformación se alimenta de unas bases comunicativas integrales y sólidas ligadas necesariamente con el entorno social y cultural y, por ende, se trata de una problemática acorde con los postulados de la teoría de la comunicación. La renovación de los objetos de estudio de la teoría de la comunicación en las dos últimas décadas presenta nuevos contextos en los que incidir teórica y metodológicamente. La aparición de entornos tan cruciales como los derivados de los estudios de la comunicación política, la comunicación intercultural o la comunicación de riesgo son una prueba fehaciente de cómo el fenómeno de la globalización en nuestras sociedades de la información nos exige confrontar la caja negra de la recepción para fortalecer nuestra sistema democrático, mejorar la comprensión de nuestra percepción de la alteridad y consolidar nuestro grado de confianza, bienestar y seguridad.

Como corolario, la tercera mundialización que nos sugiere Wolton y sus nuevos desafíos (también para la teoría de la comunicación como disciplina), que coinciden claramente con los asociados a los procesos de comunicación de riesgo y la formación de espirales del miedo:

Con el surgimiento del receptor, el siglo XXI debe comenzar a pensar de veras una política de la diversidad cultural. Si no hay opinión pública mundial, hay en cambio culturas. Reflexionar sobre las condiciones de recepción de los diferentes mensajes obliga a pensar la convivencia cultural y depende de tres fenómenos de base. Primero, no hay teoría de la comunicación sin una problemática del receptor. Esto se traducirá igualmente en 
la necesidad de admitir la negociación y, por tanto, de lentificar el proceso de comunicación, mientras que hasta ahora sólo se hablaba de acelerarlo (...) Por último, admitir la legitimidad del receptor es trastocar la jerarquía entre lo alto y lo bajo. Es, a la larga, admitir cierta igualdad, en todo caso una igual dignidad entre los diferentes participantes en las industrias de la comunicación. Tomar en cuenta el receptor es, finalmente, plantear la cuestión de la alteridad y por tanto de la convivencia, que será uno de los grandes asuntos políticos del siglo XXI (Wolton, 2004:35-6).

En consecuencia, la tradición democrática liberal, que durante largo tiempo centró sus debates en torno a la libertad individual en contraposición con la igualdad social, quizás ahora deberá poner la atención en la fraternidad humana, o en cómo lograr que la percepción del otro, y la de los otros hacia nosotros, no impliquen desconfianza y amenaza. En un entorno de globalización y desorden como el que vivimos, parece que las informaciones sobre riesgos desencadenan la formación de espirales de miedo con una cierta facilidad. Por todo ello, la Comunicación de Riesgo como campo de estudio emergente puede desempeñar un papel estratégico muy relevante.

\section{ESPIRALES DEL MIEDO, DEL CONTROL A LA EMANCIPACIÓN SOCIAL}

Muchos estudios centran su análisis en la prevención y las consecuencias de las situaciones de crisis o acontecimientos de riesgo. Otros, en cambio, se vinculan con la investigación específica de la percepción del riesgo en entornos concretos o con las áreas de comunicación de crisis, una vez éstas ya se desencadenaron, y la respuesta consiste más bien en la evaluación técnica y coyuntural de sus efectos inmediatos. En la actualidad, el campo emergente de la comunicación de riesgo plantea cuestiones de mucha más profundidad estratégica. Desde la confusión creciente entre los riesgos percibidos y los riesgos reales hasta su instrumentación, ocultación o aprovechamiento político, el incipiente objeto de estudio de la Comunicación de Riesgo define un cuestionamiento temático clave para los estudios de opinión pública, así como para la defensa del propio sistema democrático.

Cuando se asiste a la generación potencial de espirales del miedo, aquello que entra en juego son las nuevas batallas por el control de su 
gestión. Al otro lado, la apropiación sociocultural crítica y creativa es la que debe actuar para orientar su recepción activa hacia su ulterior desactivación gracias a una lógica emancipadora capaz de domesticar estas espirales, muy a menudo artificiales en su formación e ilegítimamente representadas. Cuando la visibilidad de los riesgos percibidos se acrecienta, la pérdida de control puede desembocar en acciones fuera de lugar, irreflexivas y dominadas por el miedo. En otro sentido, cuando los riesgos reales son ocultados o se procede a su invisibilidad social, tanto medios como instituciones políticas se convierten en responsables por omisión. En última instancia, la opinión pública debe ser el sujeto protagonista en la apropiación sociocultural de estas dinámicas de riesgo, dándoles un sentido liberador desde el sentido común y el ejercicio legítimo de la responsabilidad social y la acción ciudadana.

En cualquier caso, tratar de sacar provecho a este tipo de situaciones mediatizadas de crisis, riesgo, incertidumbre y miedo puede resultar coyunturalmente útil a corto plazo para algunos de los actores institucionales. Aunque las consecuencias, perversas a largo plazo, seguro que suponen un costoso lastre estructural que pone en peligro la legitimidad esencial, tanto colectiva como individual, tanto externa como interna, de los sistemas democráticos. La libertad, la participación y la solidaridad pueden abrir paso a conceptos contrapuestos como seguridad, control y desconfianza dentro de los cuales los ideales democráticos perderían toda su razón y fuerza.

\section{BIBLIOGRAFÍA}

ALTHEIDE, David L. (2002) Creating fear. News and the Construction of Crisis. New York: Aldine de Gruyter.

BAUMAN, Zygmunt (2002) Modernidad líquida. Buenos Aires: Fondo de Cultura Económica.

BECK, Ulrich (1998) La sociedad del riesgo: hacia una nueva modernidad. Barcelona: Paidós.

- (2002) La sociedad del riesgo global. Madrid: Siglo XXI.

BURnetT, J. (1998) “A Strategic Approach to Manage Crisis”, Public's Review, 24 (4).

CHARAUdEAU, Patrick (2003) El discurso de la información. La construcción del espejo social. Barcelona: Gedisa.

FUENTES Navarro, Raúl (1998) La emergencia de un campo académico: continuidad utópica y estructuración científica de la investigación de la comuni- 
cación en México. Guadalajara: ITESO/Universidad de Guadalajara.

- (2002) "Comunicación, cultura, sociedad: fundamentos conceptuales de la postdisciplinariedad", en Norma Patricia Maldonado Reynoso (coord.) Horizontes comunicativos en México. Estudios críticos. México, D.F.: Asociación Mexicana de Investigadores Comunicadores A.C., pp.11-33.

GIL Calvo, Enrique (2003) El miedo es el mensaje. Riesgo, incertidumbre y medios de comunicación. Madrid: Alianza editorial.

MURDOCK, Graham; Judith Petts; Tom Horlick-Jones (2001) Social amplification of risk: The media and the public. Contract Research Report: Health \& Safety Executive (HSE).

PIDGEON, Nick; Roger E. Kasperson; Paul Slovic (eds.) (2003) The Social Amplification of Risk. Cambridge: Cambridge University Press.

RAZGADO Flores, Luis (2002) "La comunicación política en México: propuestas para su análisis”, en Francisco de Jesús Aceves González (ed.) Anuario de Investigación de la Comunicación CONEICC IX, pp.101-132.

REGUILLO, Rossana (1999) La construcción simbólica de la ciudad. Sociedad, desastre y comunicación. México: ITESO.

- (2002) "Políticas de representación. Poder y antropología de la comunicación”, en Francisco de Jesús Aceves González (ed.) Anuario de Investigación de la Comunicación CONEICC IX, pp.37-54.

WolTON, Dominique (2004) La otra mundialización. Los desafíos de la cohabitación cultural global. Barcelona: Gedisa. 